\title{
Inertia: the discrepancy between individual and common good in dispersal and prospecting behaviour
}

\author{
María del Mar Delgado ${ }^{1,2, *}$, Irja I. Ratikainen ${ }^{3} \&$ Hanna Kokko $^{1,4}$ \\ ${ }^{1}$ Laboratory of Ecological and Evolutionary Dynamics, Department of Biosciences, University of Helsinki, Finland \\ ${ }^{2}$ Department of Conservation Biology, Estación Biológica de Doñana, CSIC, c/Americo Vespucio s/n, 41092 Seville, Spain \\ ${ }^{3}$ Centre for Conservation Biology, Department of Biology, Norwegian University of Science and Technology, Realfagbygget, 7491 Trondheim, \\ Norway \\ ${ }^{4}$ Evolution, Ecology \& Genetics, Research School of Biology, The Australian National University, Canberra ACT 0200, Australia
}

\begin{abstract}
The group selection debate of the 1960s made it clear that evolution does not necessarily increase population performance. Individuals can be selected to have traits that diminish a common good and make population persistence difficult. At the extreme, the discrepancy between levels of selection is predicted to make traits evolve towards values at which a population can no longer persist (evolutionary suicide). Dispersal and prospecting are prime examples of traits that have a strong influence on population persistence under environmental and demographic stochasticity. Theory predicts that an 'optimal' dispersal strategy from a population point of view can differ considerably from that produced by individual-level selection. Because dispersal is frequently risky or otherwise costly, individuals are often predicted to disperse less than would be ideal for population performance (persistence or size). We define this discrepancy as 'inertia' and examine current knowledge of its occurrence and effects on population dynamics in nature. We argue that inertia is potentially widespread but that a framework is currently lacking for predicting precisely the extent to which it has a real influence on population persistence. The opposite of inertia, 'hypermobility' (more dispersal by individuals than would maximize population performance) remains a possibility: it is known that highest dispersal rates do not lead to best expected population performance, and examples of such high dispersal evolving exist at least in the theoretical literature. We also show, by considering prospecting behaviour, that similar issues arise in species with advanced cognitive and learning abilities. Individual prospecting strategies and the information acquired during dispersal are known to influence the decisions and therefore the fate of individuals and, as a corollary, populations. Again, the willingness of individuals to sample environments might evolve to levels that are not optimal for populations. This conflict can take intriguing forms. For example, better cognitive abilities of individuals may not always lead to better population-level performance. Simulation studies have found that 'blind' dispersal can lead to better connected metapopulations than cognitively more advanced habitat choice rules: the latter can lead to too many individuals sticking to nearby safe habitat. The study of the mismatch between individual and population fitness should not be a mere intellectual exercise. Population managers typically need to take a population-level view of performance, which may necessitate human intervention if it differs from what is selected for. We conclude that our knowledge of inertia and hypermobility would advance faster if theoretical studies — without much additional effort — quantified the population consequences of the evolving traits and compared this with hypothetical (not selectively favoured) dispersal rules, and if empirical studies were similarly conducted with the differing levels of selection in mind.
\end{abstract}

Key words: dispersal evolution, evolutionary suicide, extinction, information, natural selection, prospecting.

\section{CONTENTS}

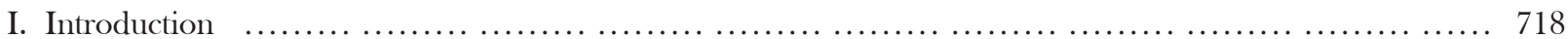

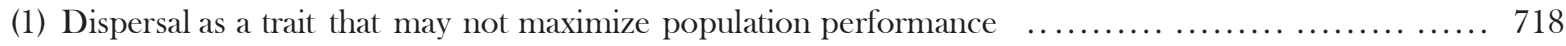

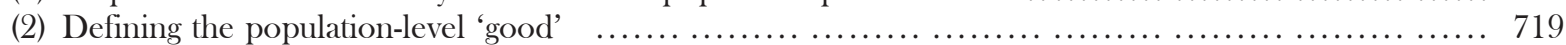

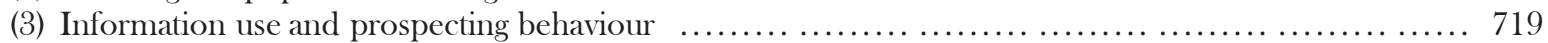

*Address for correspondence E-mail: maria.delgado@helsinki.fi 


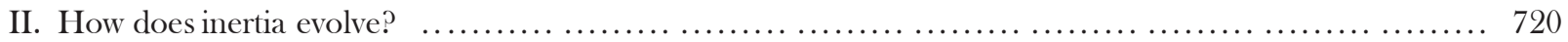

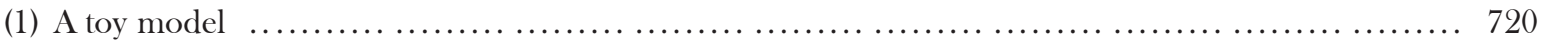

(2) A slightly more complete example: inertia and the issue of evolutionary rescue $\ldots \ldots \ldots \ldots \ldots \ldots \ldots \ldots . \ldots 20$

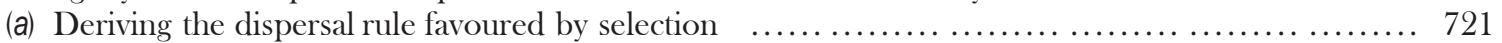

(b) Measuring inertia as the difference between the 'ideal' and the observed outcome .............. 721

(3) Is it possible to generalize when to expect inertia? Theoretical and empirical evidence from birds and other

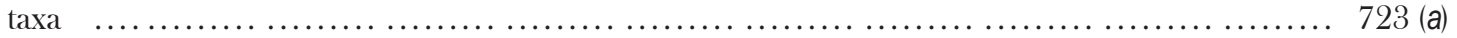

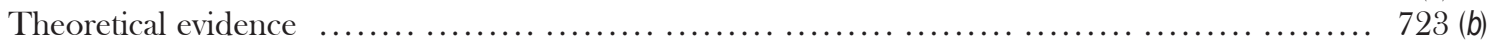

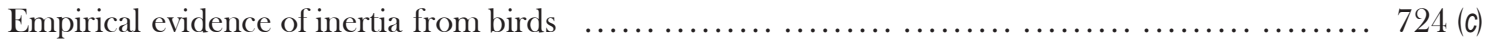

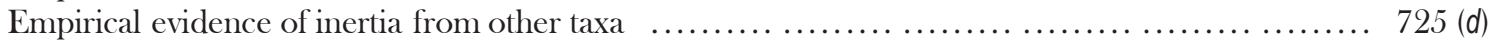

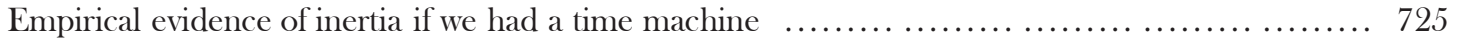

(4) Does the discrepancy always manifest itself as inertia? The case of hypermobility $\quad \ldots \ldots \ldots \ldots \ldots \ldots . \ldots 26$

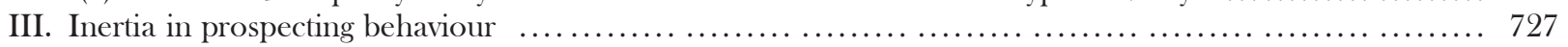

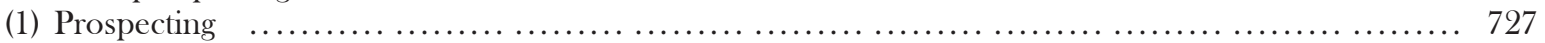

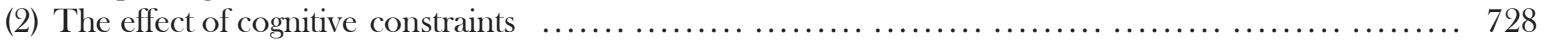

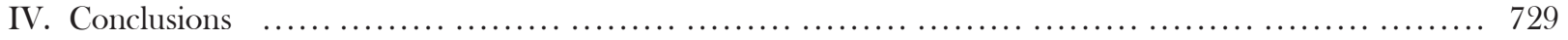

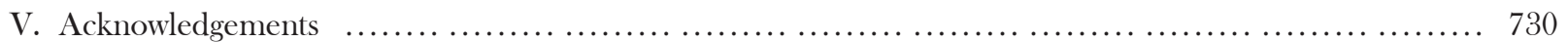

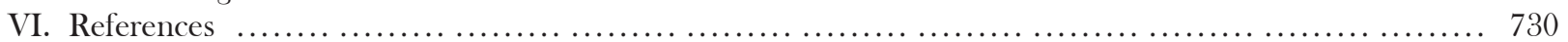

\section{INTRODUCTION}

J.B.S. Haldane (1932) was among the first to state that natural selection acting at the individual or gene level may promote traits that are advantageous for individuals but which can have disastrous effects on the population as a whole. It may appear counterintuitive that individual adaptations can have a strongly negative effect on population performance. After all, Fisher's fundamental theorem is phrased in language of increasing fitness in a population (natural selection will increase it at a rate equal to genetic variance in fitness; Fisher, 1958). Yet, this is a direct consequence of the fact that selection does not act equally strongly at all levels from genes to populations. If the individual level 'wins', the population level can 'suffer' (Rankin et al., 2007). Indeed, studies have demonstrated that selection at the level of the individual can result in poorer population growth (e.g. Muir \& Howard, 1999; Olsen et al., 2004; Dytham \& Travis, 2006; López-Sepulcre, Norris \& Kokko, 2009), difficulties of persistence (e.g. Fiegna \& Velicer, 2003) or reduced carrying capacities of environments (López-Sepulcre \& Kokko, 2005). Theoretically, it is known that natural selection under certain conditions can drive traits towards values at which a population can no longer persist at all (termed evolutionary suicide; Matsuda \& Abrams, 1994; Gyllenberg \& Parvinen, 2001; Parvinen, 2005; Rankin \& López-Sepulcre, 2005; Dieckmann \& Metz, 2006).

(1) Dispersal as a trait that may not maximize population performance

Dispersal, a topic of paramount importance in theoretical and empirical research, is a major determinant of the persistence and dynamics of populations (Clobert et al., 2001; Hanski \& Gaggiotti, 2004; Penteriani, Otalora \& Ferrer, 2006; Sharp et al., 2008). Undoubtedly, dispersal is of a benefit to populations or species as a whole. At the extreme, without any dispersal, populations would be confined to fixed spatial locations where any stochastically occurring hazard could wipe out the entire population (e.g. Van Valen, 1971; Maynard Smith, 1976; Futuyma, 1986; Lande, 1987). Palaeobiological data show that the effect of dispersal ability can extend to promoting longevity at the genus level via a correlation with geographic range size (Powell, 2007 and references therein). However, individuals do not evolve dispersal causally to ensure the survival of their populations in a far-sighted manner (Maynard Smith, 1976; Olivieri \& Gouyon, 1997). From an individual's perspective, dispersal is rarely cost-free (Denno et al., 2001; Doligez \& Part, 2008, Kisdi, 2010). Despite its costs, several (not mutually exclusive) selective forces have been proposed to promote dispersal. These include coping with resource availabilities varying both temporally and spatially (e.g. Travis \& Dytham, 1999), demographic stochasticity (Cadet, Ferrière \& Metz, 2003), and avoiding inter- or intraspecific competition for resources (Lambin, Aars \& Piertney, 2001) which is closely related to kin selection (e.g. Hamilton \& May, 1977; Comins, 1982; Kisdi, 2004), and inbreeding avoidance (Perrin \& Goudet, 2001). However, all these benefits have to be contrasted with the costs of dispersal correctly to predict the evolving dispersal behaviour (Murrel, Travis \& Dytham, 2002; Schtickzelle, Mennechez \& Baguette, 2006; Gandon \& Michalakis, 1999).

There is increasing appreciation for the fact that population-level phenomena can impact evolutionary processes (Kokko \& López-Sepulcre, 2007; Pelletier, Garant \& Hendry, 2009). While it is perhaps not widely appreciated, dispersal represents a life-history characteristic for which this interaction has been studied for a relatively long time. Olivieri \& Gouyon (1997) refer to this impact as the metapopulation effect. Despite much subsequent interest in both metapopulation ecology and the evolution of dispersal, to date researchers rarely quantify by how much evolved dispersal rates or distances deviate from maximal population-level performance (but see Olivieri \& Gouyon, 1997; Parvinen, 2004; Travis et al., 2009; Travis, Smith \& Ranwala, 2010). These examples clearly illustrate that 
there is no reason to expect that dispersal evolution at the individual level produces optimal behaviour at the level of a population. That level, however, is of obvious interest to managers interested in population (rather than individual) performance. Here our aim is to take a closer look at the predicted difference that remains after populationlevel influences on individual dispersal are taken into account.

The discrepancy between dispersal by individuals and the common good at the population level arises because there is no guarantee that the optimal balance between risks and benefits of dispersal at the individual level is the same as the balance that makes populations find new patches in the most efficient way (Lande, 1987; Matthiopoulos, Harwood \& Thomas, 2005) or maximize any other population performance measure. Given the various costs of dispersal (e.g. risks of moving in matrix habitat unsuitable for settlement, settlement in a new social environment, costs of information acquisition, energy and time expenditure), there is a directional prediction to be made: individuals are often predicted to disperse less than would be 'ideal' for the population (Olivieri \& Gouyon, 1997; Kokko \& López-Sepulcre, 2006). We shall call this discrepancy inertia, the name referring to the 'reluctance' of individuals to move in this situation (relative to the level of dispersal or prospecting that is 'ideal' for the population). By prospecting we mean sampling of environments by individuals to make informed dispersal decisions (sensu Reed et al., 1999; see below).

\section{(2) Defining the population-level 'good'}

Defining inertia as we do above, one needs to state the meaning of the word 'ideal'. It refers to the best possible population performance among all movement rules of individuals that are considered feasible for the study organism. Defining 'ideal' population performance, however, raises the obvious question of how this should be measured. While there is a quantity formally known as 'population fitness' (e.g. Fisher, 1958; Reed, 2005), defining this in a densitydependent setting is more complicated than simply equating it with population growth rate (Frank \& Slatkin, 1992), mainly because populations at density-dependent equilibrium have a long-term average growth rate of zero. Population-level performance has been measured e.g. using the total number of individuals in the entire metapopulation at equilibrium (e.g. Olivieri \& Gouyon, 1997), or the equilibrium proportion of patches that are occupied (e.g. Kokko, 2007). In our current context we prefer operationally to define the population-level 'good' as a high probability of persistence (low extinction risk), often in practice approached via proxies such as the ability of a population to find and occupy a large proportion of available habitats.

This involves some assumptions, of course: e.g. Olivieri \& Gouyon (1997), when asking questions about metapopulation survival, use the proxy of total numbers of individuals (termed carrying capacity of the metapopulation) without much justification. Persistence is obviously impossible if this predicted number is zero, and all else being equal a higher number of individuals is probably better for the future of a metapopulation. Even so, it is good to keep in mind that any concept of fitness is complicated in a metapopulation setting (Metz \& Gyllenberg, 2001) and this extends to population fitness. Such issues of definition should not distract us, however, from asking biologically meaningful and interesting questions. It is more interesting to find out that a specific dispersal rate is better for invading new areas than for occupying a large fraction of habitat within the existing range (for an example see Starrfelt \& Kokko, 2010) than it is to argue whether one or the other outcome measures population performance better.

\section{(3) Information use and prospecting behaviour}

Access to information is an important factor shaping the evolution of dispersal (Schjørring, 2002; Barton et al., 2009; Enfjäll \& Leimar, 2009). There are many species in which individuals disperse 'blindly' — wind-dispersed seeds are perhaps the most obvious example. The more advanced an organism's cognitive or sensory ability, the more likely it is that an individual's tendency to disperse depends on its perception of the suitability of its surroundings. Clobert et al. (2009) recently proposed the concept of "informed dispersal" to convey the idea that individuals gather and exchange information at all three stages of dispersal (departure, transience and settlement). In order to reduce uncertainty in the context of habitat choice, individuals need to obtain information that will allow them to make better decisions (e.g. Delgado et al., 2009) and, consequently, enhance their (inclusive) fitness. There are different strategies to gather information and assess environmental quality. For example, individuals can assess it directly from environmental cues (i.e. personal information; reviewed in Dall et al., 2005) or through socially-acquired information, using either the presence of conspecifics and/or heterospecifics (reviewed in Doligez et al., 2003) or public information such as the reproductive performance of conspecifics (e.g. Danchin et al., 2004; Sergio \& Penteriani, 2005).

Because of strong individual (or inclusive) fitness consequences, knowledge of the type of information used by individuals is important for understanding the evolution of dispersal. Individuals may be constrained by lack of information, or, when dispersal is at least partly based on copying conspecifics, informational cascades can occur if the copied behaviour is occasionally wrong (e.g. Giraldeau, Valone \& Templeton, 2002; Kosciuch \& Langerhans, 2004; Citta \& Lindberg, 2007). Since information is mainly gathered by sampling, the willingness of individuals to sample environments (i.e. prospecting, sensu Reed et al., 1999) is once again an individual-level trait that might evolve to levels not optimal for populations. Intriguingly, more information does not always improve population performance (Vuilleumier \& Perrin, 2006; see later) or individual performance (e.g. Giraldeau et al., 2002; Gilroy \& Sutherland, 2007).

We argue that dispersal and prospecting are prime examples of life-history traits experiencing the discrepancy between individual- and population-level selection. Herein 
we will explore whether, under what conditions, and to what extent natural selection can produce dispersal and prospecting rules that are suboptimal for populations. We will support this idea by providing examples that clearly illustrate how population persistence and extinction risks can be linked to these life-history traits.

\section{HOW DOES INERTIA EVOLVE?}

\section{(1) A toy model}

Consider two discrete habitat patches ('here' and 'elsewhere') and two siblings that have been born 'here'. The habitat is limiting such that in one single patch only one individual can breed. Thus, successful breeding of both individuals requires that one disperses. To produce an illustrative example, consider that each individual can produce three offspring. We can now compare the own (inclusive) fitness against the population-wide outcome of different scenarios.

If one of the two individuals disperses successfully, the twoindividual population as a whole produces six offspring and the disperser's own (inclusive) fitness equals 3 plus the effect of dispersal on improving the sibling's reproductive success, weighed by relatedness. Since the sibling would have bred with probability $1 / 2$ if neither individuals dispersed, and it breeds with certainty if it is left alone in the patch, the gain is 1.5 offspring which when weighted by relatedness $(0.5)$ adds 0.75 to a disperser's inclusive fitness, which then totals 3.75 . However, dispersal entails costs and there is a probability that the dispersing individual dies during the process. Should this happen, the value of the population-wide output and its own inclusive fitness will decrease to 3 and 0.75 , respectively. If we consider, for example, that dispersal leads to death with probability $m=0.7$, we will find that:

\begin{tabular}{|l|l|l|}
\hline & Disperse & Don't disperse \\
\hline $\begin{array}{l}\text { Own inclusive } \\
\text { fitness }\end{array}$ & $\begin{array}{l}0.3 \times 3.75+ \\
0.7 \times 0.75=1.65\end{array}$ & $\begin{array}{l}0.5 \times 3+0.5 \times 0 \\
=1.5\end{array}$ \\
\hline $\begin{array}{l}\text { Population-wide } \\
\text { output (expected) }\end{array}$ & $03 \times 6+0.7 \times 3$ & 3 \\
\hline
\end{tabular}

Note that in these fitness calculations we assume that the winner of the 'lottery' that determines which individual breeds suffers no costs of competition. In this example, both own (inclusive) fitness and the population-wide output will be higher if individuals disperse than if they avoid the costs of dispersal by remaining at the same patch. Dispersal evolution is expected to occur, although there is still conflict over which sibling disperses (to see why, note that the inclusive fitness argument in the above table assumes that the focal individual's sibling stays; if this sibling leaves and the focal individual is allowed to stay alone, its fitness is much higher still-its direct fitness alone is 3 offspring).

If dispersal mortality cost is increased to $m=0.8$, the discrepancy between individual and population levels becomes much clearer: both individuals will be more successful remaining philopatric than dispersing, despite this being not 'ideal' for the population:

\begin{tabular}{|l|l|l|}
\hline & Disperse & Don't disperse \\
\hline $\begin{array}{l}\text { Own inclusive } \\
\text { fitness }\end{array}$ & $\begin{array}{l}0.2 \times 3.75+ \\
0.8 \times 0.75=1.35\end{array}$ & $\begin{array}{l}0.5 \times 3+0.5 \times 1.5 \\
=1.5\end{array}$ \\
\hline $\begin{array}{l}\text { Population-wide } \\
\text { output (expected) }\end{array}$ & $\begin{array}{l}0.2 \times 6+0.8 \times 3 \\
3.6\end{array}$ & 3 \\
\hline
\end{tabular}

Our example intentionally oversimplifies a complex phenomenon (Hamilton \& May, 1977; Ronce, 2007); in particular, the fitness quantifications are only valid if we thereafter assume that the produced offspring compete within a much larger population. Still, this toy model clearly indicates that natural selection can in principle promote reduced dispersal rates compared with what would make the population efficient at finding suitable habitat patches.

\section{(2) A slightly more complete example: inertia} and the issue of evolutionary rescue

To study the emergence of inertia in a more complex and self-consistent setting, let us consider a metapopulation that contains $N$ habitable areas (patches) randomly distributed in space. Habitat quality is constant among these habitable areas, and all patches are equally reachable and suitable for survival and reproduction. A patch can host a maximum of $B$ breeders, thus in a patch with $n$ individuals, each adult independently produces $b$ asexual offspring if $n \leq B$, while if $n \geq B$, a randomly chosen set of $B$ adults become breeders (producing $b$ offspring each) and the others die. Offspring inherit the dispersal probability (a real number between 0 and 1) of their parent, but each offspring can independently mutate to a new uniformly distributed value of dispersal probability between 0 and 1 (such mutations occur with probability q). Parents of the first generation have randomly drawn dispersal probabilities. In addition, we introduce a degree of environmental variability in the form of a probability $p$ that a site is temporarily destroyed. When such a stochastic event occurs in a patch all individuals residing in it die. The patch is restored, and empty, in the next generation. Finally, dispersal can have a mortality cost such that a disperser dies with a probability of $m$. If it does not die, it will land on a randomly chosen patch (for an implementation of such a model see Kokko, 2007).

This ecological setting allows us to investigate the evolution of individual dispersal probability under different mortality risks. When mutation is allowed $(q>0)$, the simulation quickly converges to an evolutionarily stable dispersal probability, whereas by forcing the population to start with a predefined dispersal probability and by setting $q=0$, one can assess population performance under all other (evolutionarily unstable) dispersal rules. The dispersal probability that leads to optimal population performance (the expected number of patches occupied in the colonizationextinction equilibrium) can be sought and compared to the dispersal rule produced by natural selection. 


\section{(a) Deriving the dispersal rule favoured by selection}

To produce an example we simulated a metapopulation with a large number of habitable patches $(N=500)$ for the evolutionary time of 1000 generations. We set the other parameters at $B=b=5, p=0.05$ and $q=0.01$. In our example, dispersal probability evolves to show a U-shaped relationship

with mortality risk (Fig. 1A). This shape does not yet indicate inertia (for evaluating inertia we will have to contrast evolved outcomes with hypothetical 'ideal' ones, which we do below), but it is instructive to understand the shape itself before proceeding. The initial decline is easy to understand, while the somewhat increased dispersal probability at the highest mortalities may require some explanation. It is an example of a phenomenon that has been termed 'evolutionary rescue'. This term refers to any evolutionary change that is essential for a population to persist in new environmental conditions (Bell \& Gonzalez, 2009), and in dispersal studies it is often interpreted as selection for increased dispersal under conditions that threaten metapopulation stability (e.g. Heino \& Hanski, 2001; for a slightly different sex-specific context see Bonte, Hovestadt \& Poethke, 2009). In our example the U-shape indicates that there is stronger selection for dispersal when dispersal is increasingly risky, which appears counterintuitive at first sight, but it is explicable as a response to dramatically lowered patch occupancy when dispersal is increasingly risky. This creates conditions whereby surviving dispersal is difficult, but the difficulties are to some extent compensated as the rare successful dispersers enjoy a nearguarantee that the found habitat is vacant and thus offers good breeding prospects (Heino \& Hanski, 2001; Gyllenberg, Parvinen \& Dieckmann, 2002; Kokko, 2007).

\section{(b) Measuring inertia as the difference between the 'ideal' and the observed outcome}

At first sight, 'evolutionary rescue' appears to suggest that inertia has been overcome: dispersal rates evolve upwards and this compensates for the poorer population performance that low dispersal would have resulted in. However, as stated above, examining the evolved dispersal rule on its own cannot give us information about whether the population is responding favourably, let alone maximally favourably (as the phrase 'ideal' would imply), to the evolutionary response of higher dispersal. Rescue occurs when this response is favourable enough to steer the population away from extinction that otherwise would have occurred. Population consequences are rarely quantified in this manner, however. They cannot be directly determined from Fig. 1 either, because such plots do not contain information on how efficiently the population would have found habitats under other dispersal rules than those that did evolve. Thus, to examine the efficiency of rescue, it is useful to turn one's attention to dispersal. We thus next conduct two exercises.

First, we let a population evolve a specific dispersal rule under a fixed dispersal mortality and then change the environment (by increasing mortality) and either allow or disallow further evolution. If rescue operates, we should find cases where extinction depends on whether or not evolution is (artificially) stopped at the time of environmental change (population dynamics keeps operating whether or not evolution is allowed). Fig. 2 shows that this is indeed a possibility: at time step $t=1000$ mortality is increased from $m=0.9$ to $m=0.99$. In some cases (black lines) evolution is halted by making the dispersal probability of each individual precisely identical to the population mean of this trait at $t=1000$, as well as using mutation rate $q=0$ for all $t>1000$. In the other cases (coloured lines) mortality changes at $t=1000$ but evolution is allowed to continue as the value of $q$ is not changed within one run of the simulation. These examples show that rescue can, in principle, operate. The examples in Fig. 2 are representative in the sense that they are repeatable: running the model 100 times for each case produced 51 extinctions when evolution was stopped versus 24, 21 and 21 extinctions when evolution was allowed to continue with $q=0.0001,0.005$ and 0.01 , respectively. Simultaneously,

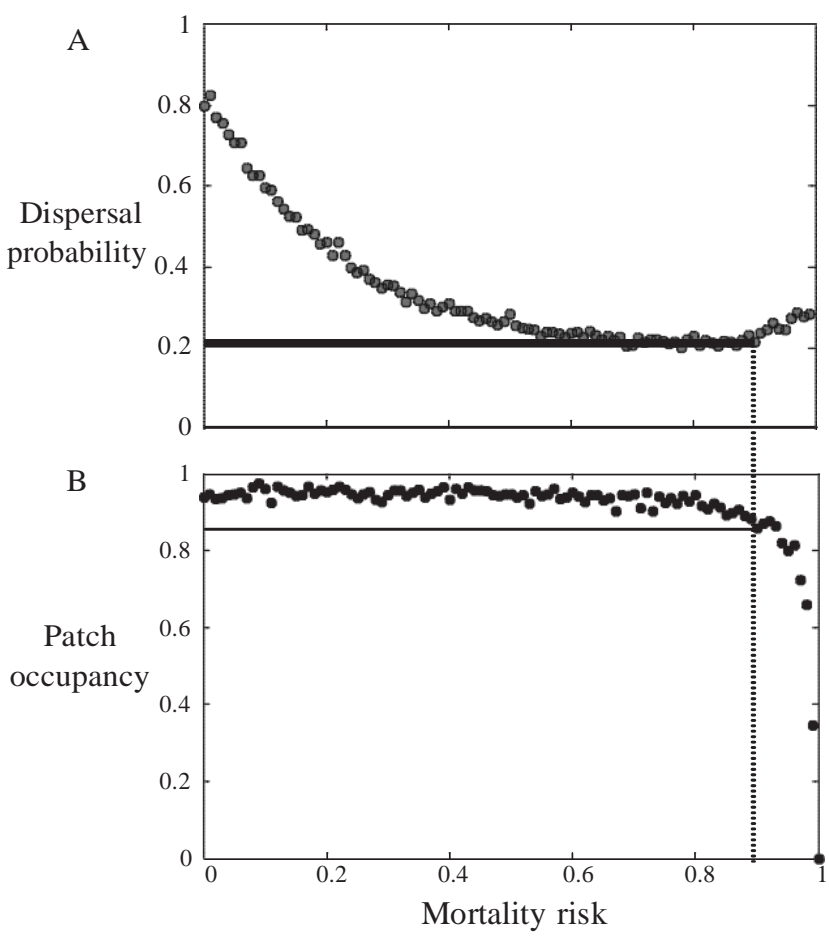

Fig. 1. The evolved dispersal probability (A) and the proportion of patches occupied (B) as outcomes of single simulation runs (see text for details), each with a different values of dispersal mortality $\mathrm{m}$. The dotted lines indicate an example where $90 \%$ mortality leads to greater than $80 \%$ of patch occupancy, but this relies on assuming a dispersal rate of about $20 \%$, thus this value in itself does not allow us to state what patch occupancy rates were possible with this value of mortality $m$ were the population to disperse at a different rate. Parameter values: $N=500$, $B=b=5, p=0.05, q=0.01$, where $N$ is the number of patches, $B$ the number of breeders per patch, $b$ the number of offspring per breeder, $p$ the probability that a patch becomes unsuitable in a given year, and $q$ the mutation rate for the dispersal trait. 

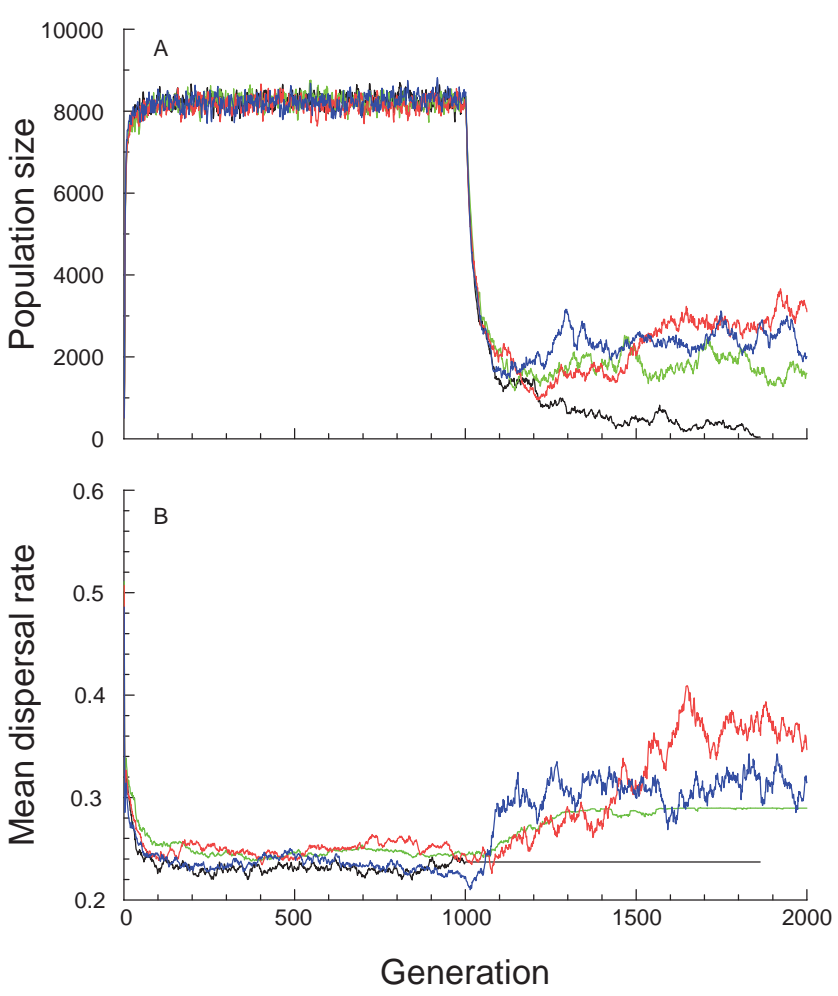

Fig. 2. An example of evolutionary rescue. The population is initiated as in Fig. 1, but after 1000 generations mortality is suddenly increased from $m=0.9$ to $m=0.99$. The black line shows a population that experiences mutation rate $q=0.01$ until $t=1000$ and thereafter stops evolving (all individuals are assigned dispersal traits equal to the population mean and $q$ is set to 0$)$. The population goes extinct at generation 1863 . Other populations use $q=0.0001$ (green), $q=0.005$ (red) or $q=0.01$ (blue) and persist. See main text for the generality of these findings.

however, these results only form a proof of principle that rescue can lead a population safely through a bottleneck rather than showing how wide the circumstances (such as the speed and magnitude of changing dispersal risk) are under which rescue operates efficiently. This example simply highlights the need for further work.

Second, we can look in detail at patch occupancy for different dispersal rates, assuming a specific (fixed) mortality risk during dispersal. This is interesting for answering the question of whether, even in those cases where populations survive, evolution might produce population performance that nevertheless falls below an ideal level that it could reach in principle. In our original example (Fig. 1) we assumed a relatively large growth rate $(B=b=5)$ and thus at equilibrium, the proportion of patches occupied is over $80 \%$ despite high dispersal mortality and a low (just over 20\%) dispersal propensity (Fig. 1). Keeping a focus on specific values of $m$ (say $10 \%, 90 \%$ or $98 \%$ mortality), the simulation can be rerun with forced (non-evolving) dispersal probabilities, to see if some of these perform better than evolving probabilities.

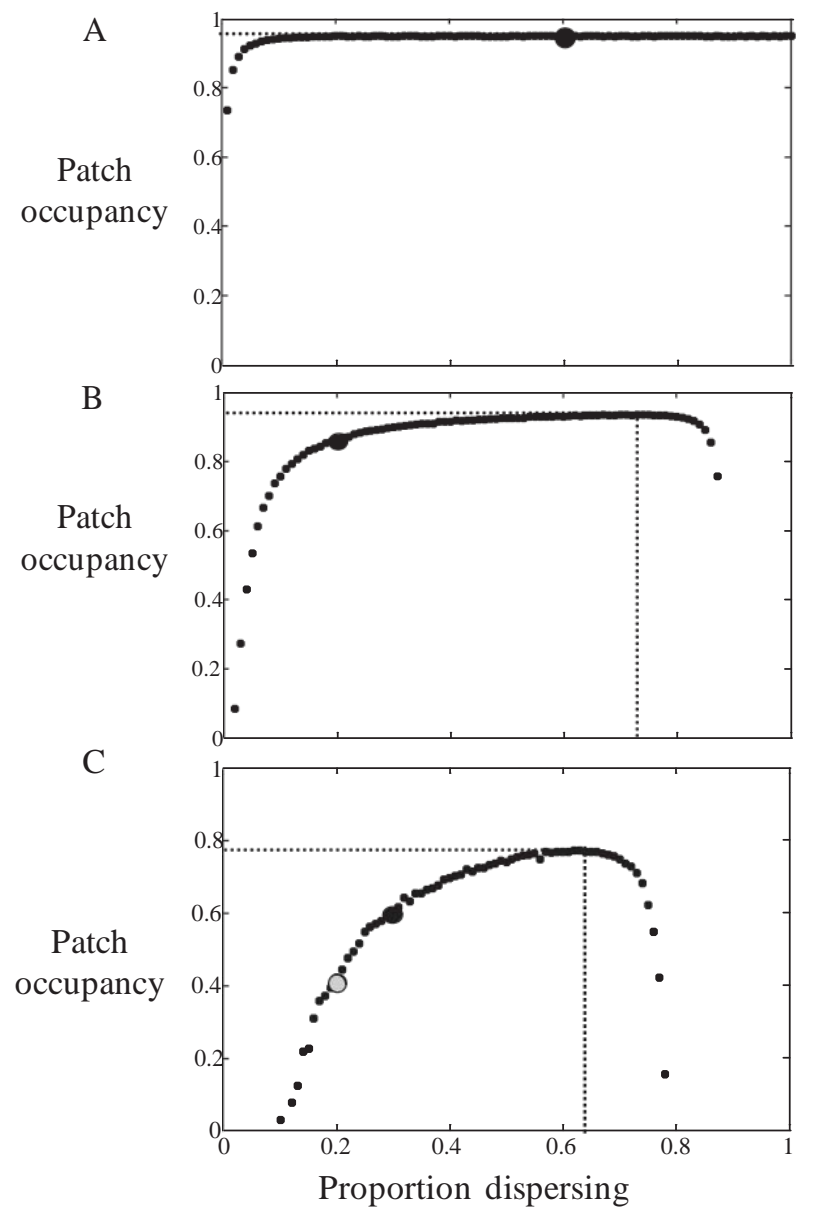

Fig. 3. Mean proportion of patch occupancy as outcomes of single simulation runs when individuals were forced to use a certain dispersal probability as indicated on the $x$ axis. Dispersal mortality is fixed at (A) $m=0.1$, (B) $m=0.9$ or (C) $m=0.98$. Other parameters: $N=500, B=b=5, p=0.05$ (see Fig. 1 for parameter definitions). Dotted lines indicate best achievable population-level performance. The large black dots indicate the dispersal rate favoured by natural selection (read from Fig. 1A) and its population consequence, the small dots depict consequences of all other dispersal rates. The grey dot in $\mathrm{C}$ indicates patch occupancy in a population that fails to evolve upwards from the lowest dispersal rate produced in Fig. 1A as mortality increases; the vertical difference between the grey and the black dot measures the efficiency of evolutionary rescue (see main text for details). The dotted lines indicate the highest population performance measured as patch occupancy at equilibrium.

The results (Fig. 3) clearly show that there are conditions that show no inertia: with $m=0.1$ (Fig. 3A), the evolving dispersal strategy (large dot) produces a population performance as good as possible with the given dispersal mortality $m$ and patch destruction rate $p$. In other words no other dispersal rate (small dots) brings about superior population-level occupancy. However, when mortality risk is high $(m=0.9$ (Fig. 3B) and 0.98 (Fig. 3C)), evolved dispersal rates (large dots) fall greatly short of what would lead to 


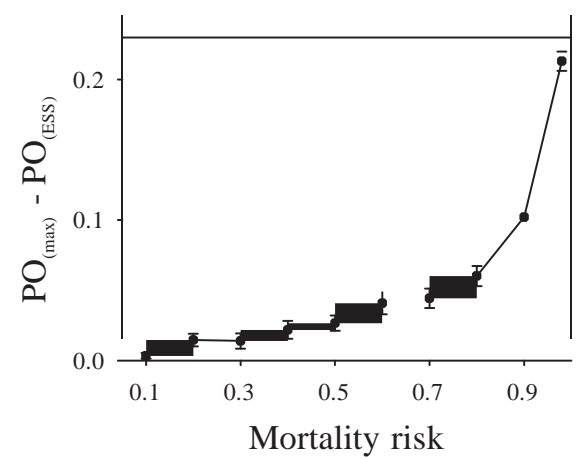

Fig. 4. Difference between the maximum patch occupancy $\mathrm{PO}_{(\max )}$ ('optimal' from a population viewpoint) and the proportion of patches occupied with an evolutionarily stable strategy $\mathrm{PO}_{(\mathrm{ESS})}$ ('optimal' from an individual viewpoint) at different mortality risks. For each value of mortality risk we represented the mean value $( \pm 95 \%$ confidence intervals) of 10 simulations. Positive values indicate that inertia is selected for, and this discrepancy between individual- and population-level good increases clearly when $m>0.7$.

highest population performance, measured as the number of patches occupied at equilibrium. The discrepancy between individual and population level shows itself as clear inertia. Inertia in our example increases sharply after $m=0.7$ (Fig. 4).

These results suggest that inertia can be strong. They can also be used to assess whether evolutionary rescue (slightly more dispersal at the highest than at moderately high mortality values) truly counteracts inertia. To aid this comparison, we have additionally marked a grey dot in Fig. 3C. In Fig. 3C mortality is so high $(m=0.98)$ that it falls within the zone where the population is predicted to evolve back towards higher dispersal, i.e. a 'rescue' (Fig. 1A). The difference between the large grey and the large black dot in Fig. 3C indicates the efficiency of this rescue in the following way. To assess whether rescue operates efficiently, we need to evaluate whether the slight increase of dispersal rates at high mortality values in Fig. 1A matters in terms of population persistence. Thus we have to compare the population consequences of (i) remaining at a $20 \%$ dispersal rate (lowest point in Fig. 1A) while dispersal mortality is further increased to close to 1, with (ii) evolving the 'rescue' dispersal rate of close to $30 \%$ (end of Fig. 1A) while dispersal mortality is close to 1 . The grey dot in Fig. 3C depicts the population consequences of evaluation (i), the black dot the consequences of evaluation (ii). Their difference shows that the rescue lifts populations to a patch occupancy of $60 \%$ (black dot) instead of $40 \%$ (grey dot). This is no doubt an improvement, but simultaneously it remains an incomplete compensation for the higher mortality that underlies the very evolution of this 'rescue'. When dispersal mortality was not yet high enough to prompt a rescue (lowest point in Fig. 1A), individuals only needed to show a $20 \%$ dispersal rate and this allowed them to fill $80 \%$ of the habitat - much more than either the rescued (black) or non-rescued (grey) points in Fig. 3C.
(3) Is it possible to generalize when to expect inertia? Theoretical and empirical evidence from birds and other taxa

\section{(a) Theoretical evidence}

Although our term 'inertia' has obviously not existed in the literature in the current context, the idea behind it has a relatively long history. Confirming suggestions from early simple models by Levins (1970) and Van Valen (1971), Roff (1975) demonstrated that the 'optimal' dispersal strategy from the population point of view could differ considerably from that produced by individual-level selection. He analyzed a one-locus, two-allele model where one allele produced a nondisperser phenotype and the other allele caused dispersal with a fixed probability (different versions of the model differed in what heterozygotes were assumed to do), and he derived quantitative genetic results. Populations did not evolve to be as 'fit' as possible, including cases where populations were driven extinct as non-dispersers became 'too common'. Such 'suicidal' evolution has been documented in other evolutionary models (Gyllenberg et al., 2002; Parvinen, 2007).

To this day, however, it appears understudied how various dispersal rules and their relationship to the ecological characteristics of populations (e.g. stability, habitat fragmentation, food and territory availability) determine the strength of this discrepancy and thus the magnitude (or existence) of inertia. For example, in Figs 1-3 we predict inertia to be strongest when disperser mortality is high, but the generality of this prediction is unknown - although Roff's (1975) examples of extinction, perhaps unsurprisingly, also assumed high disperser mortality.

Inertia is perhaps intuitively expected to be most pronounced when population persistence is already at risk (compare Fig. 3B,C with Fig. 3A). This makes the increasing appreciation for the patchy nature of most environments (e.g. Boudjemadi, Lecomte \& Clobert, 1999; Baskett, Weitz \& Levin, 2007) relevant for our context. Where there is unevenness across a landscape, dispersal is not only essential for connections among patches and thus for the persistence of metapopulations (Hanski, 1998), but also risky for individuals. Simultaneously, local survival of subpopulations in fragmented patches may be low. Such conditions could pose the greatest risk that selection for 'inert' individuals may affect the evolutionary future of populations, although once again we know of no systematic study across diverse conditions. Insofar as fragmentation is expected to increase dispersal mortality, Fig. 1 suggests that more fragmentation often leads to lower dispersal, not higher as in the evolutionary rescue scenarios.

Current models of inertia and evolutionary rescue may underestimate the importance of dispersal, however. Selection against dispersal in fragmented landscapes (Cody \& Overston, 1996; Travis \& Dytham, 1999; Heino \& Hanski, 2001; Schtickzelle et al., 2006) or under different ecological characteristics such as high levels of competition for nest sites (McCarthy, 1997, 1999) has other adverse effects beyond patch-finding as envisaged in Figs $1-2$. It limits gene flow among populations and can lead to prolonged effects 
of inbreeding after founder events (Hansson et al., 2002). Given that negative fitness consequences of inbreeding are a potentially strong causal factor enhancing dispersal (Bowler \& Benton, 2005), it may appear surprising that inbreeding itself can hamper dispersal (Bonte, 2009). Yet this evidence becomes understandable given that dispersal requires energy reserves and thus it is a trait potentially subject to inbreeding depression (Bonte, 2009). It follows that small populations subject to environmental and demographic stochasticity may suffer the double whammy of high local extinction risks and limited capacity to recolonise empty patches (Opdam, 1990). Thus, the demographic scenarios where inert individuals may lead the metapopulation to evolve itself to death (Gyllenberg \& Parvinen, 2001; Gyllenberg et al., 2002; Parvinen, 2005) could underestimate the true population-level cost (inertia) once genetic effects are taken into account.

\section{(b) Empirical evidence of inertia from birds}

Birds form a well-studied taxon in which population declines in fragmented natural habitats are related to populations becoming isolated and diminished in size as habitat degradation increases due to human alteration; this may restrict dispersal movements among fragments (e.g. Sieving, Willson \& De Santo, 1996). Many bird populations have been confined to small and separated habitats after humaninduced modification of the original landscape (e.g. North Island brown kiwi Apteryx australis mantelli, Potter, 1990; Dupont's lark Chersophilus duponti, Vögeli et al., 2010). In Australia, brown treecreeper (Climacteris picumnus) populations are declining, and females living in fragmented Eucalyptus forests are very reluctant to disperse between small habitat fragments (Cooper \& Walters, 2002). Males usually do not disperse, but inherit territories in their natal patch, and as a consequence a large proportion of males remain unpaired in such populations (Cooper \& Walters, 2002). It is known that productivity and mortality are similar in territories in fragmented and contiguous habitat (Cooper \& Walters, 2002). Despite this, the number of female breeders in fragmented habitat has decreased over time due to a lack of immigrant females, and a simulation model showed that population sizes will decrease as a result (Cooper, Walters \& Priddy, 2002).

The study of Cooper et al. (2002) is additionally intriguing as it highlights how the difference between individualand population-level optima of dispersal can be especially pronounced when differences between the sexes are acknowledged. Female-biased dispersal, as is common in birds, has been argued to lead to higher extinction probabilities, because it makes females - the more important component of reproductive performance of a population - subject to the higher risk of dispersal and creates male-only population fragments which have obviously lost their reproductive capacity (Dale, 2001). Taken in the context of our review, however, the arguments of Dale (2001) suggest that females disperse 'too much' for the good of the population, which is opposite from what the concept of inertia entails. We will discuss more such suggestions of inertia's opposite - which we term 'hypermobility' — in detail in Section II.4. For now, it is perhaps best concluded that making a firm statement for the direction of the discrepancy between individual- and population-level good in the case of sex-biased dispersal is even more premature than for asexual cases. We know of no study that has explicitly studied population consequences including sex-specific costs that arise due to biased dispersal and the fact that, without female dispersal, populations may fail to establish in new areas (also note that in many taxa, like birds, both sexes need to be present in a new area before a population can establish itself).

As another example of inertia, ovenbirds (Seiurus aurocapillus) have been found to be reluctant to move between isolated patches after the onset of fragmentation and were hence packed into the remaining habitats (Hagan, vander Haegen \& McKinley, 1996). Breeding success in the newly denser fragments was lower, possibly due to some behavioural dysfunctions associated with higher competition for limited resources (Hagan et al., 1996). Social disorder in high-density populations can intensify extinction risk (see also LópezSepulcre et al., 2009), but reduced performance is also simply predicted as a result of density dependence in such scenarios.

A similar pattern was found by Strong \& Bancroft (1994) when studying the large frugivorous white-crowned pigeons (Columba leucocephala). White-crowned pigeons may play a pivotal role as seed dispersers in south Florida's ecosystem because of their mobility, fairly large population size, diet diversity, and tendency to pass most seeds intact. However, this species has a behavioural inhibition to disperse, and individuals living in highly fragmented habitat need large forest fragments as 'stepping stones' to disperse to more distant areas where habitat availability is less restricted. If these refuges of adequate size for these species are not presented or disappear, these birds may be particularly prone to extinction.

How well these examples support the idea of inertia is open to judgement, as studies are rarely able to measure how much better the population would fill available habitat patches if dispersal rates were higher (e.g. forcibly enhanced). Neither is it measured how well individuals would do with higher rates or probabilities of dispersal, and it is not unlikely that individual fitness would increase with more dispersal in some of the systems presented. While we may lack controlled experiments, one could argue that successful translocations of individuals of endangered species show that the population had been suffering from inertia: it only failed to find all available habitats because its individuals did not leave to go there. Some invasions fall into this category too, as invasions are often the result of an unintentional translocation.

Strictly speaking, inertia interpretations of such cases requires that individuals making the move on their own would have fared equally well as those translocated - to begin with, they should not only survive the journey but also find a mate upon arriving in the new area. This may again be hard to prove, however in some cases individuals show such reluctance to move even short distances that inertia is very likely. The Seychelles magpie robin Copsychus sechellarum, for example, used to inhabit the entire Seychelles archipelago 
but by the early $1990 \mathrm{~s}$ it was confined to just one island (Komdeur, 1996). Following habitat restoration, predator removal and translocations it now breeds on four islands (López-Sepulcre et al., 2009). Although some of the islands are located very close to each other (the shortest distance between the shores of Cousine and Cousin is $2.04 \mathrm{~km}$ ), colour-ringing reveals that these birds, fully capable of flight, hardly ever arrive on other islands as immigrants (Shah \& Parr, 1999). Although speculative, it appears reasonable to argue that the isolation of the Seychelles from any large body of land might have strongly selected against a tendency to cross bodies of water of any size. The power of such selection is perhaps most persuasively seen in another taxon: Apterocyclus honolulensis beetles that inhabit isolated oceanic islands have fully developed wings that cannot be used because the wing covers are fused, preventing wing opening (Futuyma, 1998).

Recent evidence that microevolution itself can be slower in birds confined to small islands (Wright et al., 2009) is also intriguing to consider. Wright et al. (2009) make the case that these slow rates indicate constraints on the ability of populations to adapt to current or future environmental change. If one includes dispersal among the set of traits that ought to respond to changed environments, then the reduced adaptability of small populations could, paradoxically, in some cases prove a blessing. Such a hypothetical scenario where populations benefit from reduced adaptability can happen if individuals fail to evolve towards lower dispersal rates in increasingly fragmented habitats (i.e. despite higher mortality risk dispersal may fail to 'fall' as predicted across most parameter values of Fig. 1A), and metapopulation-wide viability demands preserving high dispersal. Currently though we know of no empirical evidence of this, which would require not only measuring inertia but also measuring the lack of evolutionary response compared with what individuals are expected to evolve towards.

\section{(c) Empirical evidence of inertia from other taxa}

Other taxa that have suffered from recent habitat fragmentation are amphibians and insects, and attempts have been made to quantify the effect of dispersal on extinction probabilities in these groups. An analysis of survival of 56 species of butterflies in parts of Europe showed that species of intermediate mobility showed the highest extinction rate and lower local population sizes (Thomas, 2000). This result is in rather curious contrast with predictions stating that intermediate dispersal rates tend to lead to the best prospects for population persistence (Olivieri \& Gouyon, 1997; see also Kneitel \& Miller, 2003). However, an important difference between the theory and empirical example may be that this analysis looked at dispersal distance while the model used dispersal rates. The pattern could perhaps be explained by intermediately mobile species leaving their birth habitat and not reaching another suitable breeding fragment, thus not achieving the benefits of either high connectivity with much dispersal or low risk associated with little dispersal. It should also be noted that model predictions are based on within-species variation and consequently do not take differences into account that result, for example, from differences in habitat availability for the different species.

Pond-breeding amphibians live in a less stable environment than many other amphibians and populations are highly dependent on their dispersal abilities because of relatively frequent local extinctions. Habitat fragmentation therefore is more likely to affect populations of pond-breeding amphibians than other groups of amphibians (Green, 2003). This is also supported by other studies: amphibian species that have high dispersal ability are more affected by habitat loss and fragmentation (Gibbs, 1998; Cushman, 2006), suggesting that species that are more dependent on dispersal are more adversely hit when dispersal is curtailed. However, in the long run, species with limited dispersal abilities are equally imperilled (Cushman, 2006). For example, in the southern part of the province of Limburg in The Netherlands, changes in agricultural landscapes led to a situation where small habitat islands were surrounded by an inhospitable habitat. The strength of isolation effects reflects the degree to which the landscape has been altered by human development, and dispersal became very difficult for certain species of amphibians. Of the original twelve species present in the area, two became extinct and five were endangered (Laan \& Verboon, 1990).

Mammals constitute another taxon in which restricted dispersal could lead to population decline or, even worse, to population extinction. The euro Macropus robustus is a large kangaroo, and Arnold, Steven \& Weeldenburg (1993) studied six populations embedded in the agricultural areas of Western Australia. This species persists in those areas because the land was too rocky to clear and cultivate. Kangaroos can cross open farmland by using native vegetation cover, allowing the movement of individuals between and within populations (Arnold et al., 1993). However, the movement rate between populations is low and limited by the spatial arrangement, the connectivity and the distance between populations. In the two populations with lower native vegetation, density of these kangaroos was extremely low. The remnants of such populations were small, widely scattered and little connected. Solitary males and females living in these populations only sporadically found each other, with negative productivity consequences. In addition, individuals forced to live in these suboptimal habitats are exposed to higher mortality rates of young due to predation. Again, however, while the euro joins a large list of populations adversely impacted by fragmentation, linking such results with the concept of inertia would require assessing to what extent more mobility would counteract the negative impacts of existing fragmentation. We are not aware of studies that have attempted this.

\section{(d) Empirical evidence of inertia if we had a time machine}

All examples presented above show the results of "unintended manipulations", where populations have been restricted in their dispersal because of relatively recent changes in the environment. Such studies are highly relevant in a time of large-scale climate change, the greatest unintended experiment of all time (Bell \& Collins, 2008). 
Inertia in this context can occur (or pre-existing inertia can become stronger) in two ways: firstly, individuals may experience selection towards lower dispersal rates which proves maladaptive from a population point of view (Fig. 1). Alternatively, evolutionary constraints, such as lack of genetic variation, may leave dispersal traits unchanged when a population perspective requires more movement than before (to track shifting climates). In such a case it is likely that the current dispersal rates or distances are neither optimal at an individual nor population level. Evolution may change this over time unless extinction occurs first, but since we predict that inertia can prevail even when populations are at evolutionary equilibrium, maximal performance at the population level will rarely be achieved. It would therefore be very interesting to see the results of experiments where the need to disperse was increased in a controlled way. This may be a hard task, but may prove an important test of the models presented above.

(4) Does the discrepancy always manifest itself as inertia? The case of hypermobility

Thus far we have been concerned with causes and consequences of inertia, and seen that natural selection does not necessarily promote individual behaviours that are 'good' for populations. However, our suggestion that the discrepancy between individuals and populations will always take the form of inertia, i.e. less movement than 'ideal' for populations, is a stronger claim. It is in principle possible that individuals are selected to move more than what is optimal for the population: a reversal of inertia, which we call hypermobility. In fact, an early model by Hamilton \& May (1977) suggested that evolutionarily stable dispersal rates are greater than the species optimum. This is quite the opposite of what was found by Roff (1975), but the discrepancy can be explained by the difference in the type of stochasticity in their models (Comins, Hamilton \& May, 1980; Olivieri \& Gouyon, 1997). The model by Hamilton \& May (1977) does not have any exogenous extinction, and without environmental stochasticity dispersal does not give the same advantage at the metapopulation level.

When exploring the impact of dispersal on populations, Bowler \& Benton (2009) showed that the effect of dispersal on population performance is not always positive, especially when looking at the population growth rate. In their mite system, they observed that patches connected with either short or long tubes displayed slower population growth than populations kept isolated such that dispersal was not permitted. A similar result was obtained in an experiment restraining dispersal of planthoppers and their parasites, as caged populations had the highest density of both the planthoppers and their parasites through several generations (Cronin, 2007). In fact, population growth can sometimes be inversely related to dispersal distance (Schtickzelle \& Baguette, 2004), and in the context of parent-offspring conflict over dispersal, Starrfelt \& Kokko (2010) showed that offspring-controlled dispersal can be expected typically to evolve to be shorter than maternally controlled dispersal yet it also leads to better habitat utilization.
Such results suggest that the opposite of inertia, i.e. hypermobility, remains a possibility. Whether these results should overturn the earlier suggestion that individuals usually disperse less relative to what is optimal for populations (Olivieri \& Gouyon, 1997) is an open question. This open question becomes even more difficult to answer when considering that population growth is the result of the complex interaction between dispersal, temporal correlation and spatial heterogeneity (Schreiber, 2010). Even though dispersal in the presence of temporal and spatial fluctuations can enhance metapopulation growth rate, in themselves these terms can reduce it (Schreiber, 2010). Oversimplifying a complex process, however, one could speculate that inertia will become much more prevalent in the future if climate change causes extinctions of populations that fail to shift polewards or (in mountainous areas) upwards (Thomas, Franco \& Hill, 2006; Brooker et al., 2007).

Many of our above examples consider dispersal a genetically determined rate or model it as a kernel that is under genetic control (see Ronce, 2007). In organisms that rely on local cues for dispersal, there are further reasons why hypermobility might occur. For example, territories of the most endangered species of the Felidae, the Iberian lynx (Lynx pardinus), in the National Park of Donana (southwest of Spain) are located in isolated patches of breeding habitat with metapopulation properties and source-sink dynamics (Gaona, Ferreras \& Delibes, 1998). The high protection of the park ensures that patches located inside have a high rate of survival, while outside the mortality risk is high for all individuals. The dynamics and persistence of this system is influenced by the matrix heterogeneity used by individuals during dispersal. Dispersing lynx are able to use information on matrix heterogeneity, the proximity of breeding areas and on mortality risk in open areas. When simulating different landscape scenarios, Revilla \& Wiegand (2008) found that not only the proportion of habitat suitable for dispersal but also its configuration had a strong effect on the demographic status of this small and fragmented metapopulation. Configurations where most dispersal habitat occurred next to breeding habitat (thus preventing long-distance dispersal to areas with no breeding habitat) reduced the number of animals that became lost far from focal sites. This helped to lower extinction probabilities. Randomly distributed dispersal habitat did not predict as good population performance, but even this was better than population performance in the configuration of the real landscape. Revilla \& Wiegand (2008) also found that in the absence of any dispersal corridors, individuals were predicted to float close to their natal population so that they could be locally recruited whenever a vacancy in the breeding area occurs, and this 'fencing' effect resulted in higher local occupancy rates (Revilla \& Wiegand, 2008).

In some cases the loss of connection among populations can lead to disruption in the local social environment and this can eventually increase dispersal rates again. For example, Boudjemadi et al. (1999) found higher density of common lizards (Lacerta vivipara) in fragmented and isolated than in nonfragmented populations. The social disruption associated 
with the increased lizard density forced the less-competitive individuals to disperse. Since these individuals experienced higher rate of mortality, the higher motivation of individuals to move could have a detrimental effect for the population as a whole, although the net effect on populations was not quantified (loss of connection also had intriguing negative consequences as female reproductive rates diminished across habitats). Other social factors, such as the lack of mates, can drive the last individuals inhabiting small patches at low population density to emigrate, and thus dispersal could finally be the cause of extinction in those patches (Andreassen \& Ims, 2001) although once again the population-wide consequence of such a response could be positive.

We strongly recommend that future studies should strive to measure the discrepancy (inertia or hypermobility) between individual- and population-level performance. This task is, however, complicated by the further caveat that the behavioural rules used by individuals may fail to maximize either individual- or population-level fitness. Reasons for this vary from temporally changing environments, discussed above, to more fundamental reasons why evolution can fail to optimize (Metz, Mylius \& Dieckmann, 2008; Orr \& Unckless, 2008). In a colony of western gulls Larus occidentalis philopatric males were characterized to have in general more dominant phenotypes, hatching earlier in the season and with both higher prebreeder survival and recruitment probability (Spear, Pyle \& Nur, 1998). Philopatry increased local population size but philopatric males survived significantly less well than dispersive males, leading Spear et al. (1998) to suggest that this level of dispersal avoidance appears maladaptive for individuals. With correlative data it is, however, hard to evaluate whether philopatric individuals would gain the same reproductive success as dispersers, had they dispersed too.

\section{INERTIA IN PROSPECTING BEHAVIOUR}

\section{(1) Prospecting}

The term 'prospecting' refers to sampling of spatial and nonspatial information with the aim of collecting information for future breeding-site-choice decisions. Previous studies suggest that prospecting is a phase of several behavioural changes and decisions (Reed et al., 1999), in which the conditions experienced and the information acquired can influence the decisions and therefore the fate of individuals and, as a corollary, populations. In temporally predictable and patchy environments, acquiring information is expected to enhance individual fitness (Boulinier \& Danchin, 1997), at least if the acquisition process itself is not too expensive in time and energy (Giraldeau et al., 2002).

Prospecting may stabilize population dynamics (e.g. Ruxton \& Rohani, 1999), making populations less likely to go extinct. However, because there is no guarantee that individual optimality coincides with population-wide optimality, under certain circumstances individuals may be selected to prospect less than would be 'ideal' for populations. A simulation model of the evolution of prospecting strategies gives analogous results to what has been found for our previously described dispersal model (I.I. Ratikainen \& H. Kokko, in preparation). When the cost of prospecting is high, several parameter combinations give lower population performance when populations are allowed to evolve their prospecting strategies compared to scenarios where prospecting strategies are set to the population optimum. Moreover, it is likely that the quality of information available for individuals within a population varies (Parejo, Oro \& Danchin, 2006; Citta \& Lindberg, 2007). The pattern observed at the population level may then not reflect the decision rules for an 'average' individual, particularly if conspecific copying plays a role (Parejo et al., 2006).

The most important aspects determining whether individuals will prospect, which will also be affecting the efficiency of this behaviour, are the availability, the quality and the spatiotemporal predictability of the information (Schjørring, 2002). There is empirical evidence showing that individuals could be constrained by lack of information or cues that are "spatiotemporally unavailable” (Doligez et al., 2004). This can lead to underutilization of habitats in two opposing ways: because occupied habitat is avoided, or because unoccupied habitat is avoided. To understand the first case, consider a territorial species in which individuals gather information on available breeding positions and territory quality throughout intrusions (Stamps, 1994). As proposed by some behaviour-based models on territory acquisition, more intrusions in a certain area will allow individuals to obtain more detailed knowledge of the social environment and will increase the chance of obtaining a vacancy in that area (Stamps \& Krishnan, 1999, 2001; Bruinzeel \& van de Pol, 2004). However, when intrusions come with high risks of mortality or serious injury, prospecting can be selected against. For example, in a high-density population of eagle owls (Bubo bubo) in south-western Spain, emigrating individuals with a limited dispersal distance settle to occupy non-breeding areas that are close to their natal population but nevertheless spatially distinct (Delgado et al., 2010). Owls stay there for several years without exploring their natal or other potential breeding populations. This lack of prospecting creates limited flow back to their natal area (Delgado et al., 2010), which has the effect that dispersing individuals are not observed ever to recruit back into any breeding population. In a predatory species that has obvious means to inflict damage on conspecifics in fights it is perhaps explicable, in a proximate sense, that owls become inert in their settlement areas, disconnected from the breeding population. At the level of an ultimate explanation this behaviour is a mystery, however, as it leads to no observable lifetime reproductive success for dispersers. For the population, such behaviour, if common, implies long waiting times before vacant territories are filled (Lande, 1987) when an owner dies. Since dispersers do not gather information about the breeding population, any vacant territory will be empty for long periods (V. Penteriani \& M.M. Delgado, in preparation).

The opposite pattern, avoidance of unoccupied habitat, can occur in species where conspecifics attract prospectors. 
Curiously, this may lead to the same effect of not enough prospecting, or, despite intense prospecting efforts, decisions not to disperse even if there is available breeding habitat. Absence of conspecifics - e.g. due to entirely stochastic reasons - may render apparently suitable habitat unoccupied for long periods (Laiolo \& Tella, 2008; Ahlering \& Faaborg, 2006), and lack of prospecting effort in these areas could have the potential to cause the decline of populations. Studies on aggregation patterns in Drosophila spp. similarly show that conspecific attraction can lead to good ovipositioning sites remaining empty (Shorrocks \& Rosewell, 1987). Although in most cases socially acquired information is expected to be beneficial, individuals imitating incorrect behavioural decisions can easily fall into informational cascades (Giraldeau et al., 2002) which in the context of habitat choice implies overcrowding in certain areas and simultaneous underuse of habitats in others.

Overreliance on cues can be costly if it attracts individuals into sink habitats where they have little chance of breeding successfully (ecological traps; Gilroy \& Sutherland, 2007), or if it keeps individuals in source habitats when the density has increased to the point that per capita success becomes nullified. In species where public information or social attraction is important for settlement decisions, the high levels of philopatry found in some high-density breeding areas could thus be a case of inertia related to the social behaviour of individuals (Forero, Donázar \& Hiraldo, 2002; Serrano et al., 2004; Sergio \& Penteriani, 2005; Péron, Lebreton \& Crochet, 2010). Given that density dependence often predicts poorer per capita performance in high-density habitats, it is curious that individuals of many species prefer to settle near conspecifics (Nocera, Forbes \& Giraldeau, 2006; Fletcher, 2007). Such preferences become understandable, however, if the presence of conspecifics provides sufficiently important information (Seppänen et al., 2007), or if negative density dependence is diminished - or possibly reversed to positive density dependence - by positive impacts of conspecifics (Allee effects such as dilution of predation risk, or defence against predators in colonies, Serrano et al., 2005).

In keeping with the general theme of this review, though, there is little guarantee that individuals perfectly balance the positive and negative aspects for the whole population of settling near conspecifics. While a simple comparison between random and informed settlement predicts that the latter leads to better population performance (Greene, 2003), it is possible that individuals in real life use rules of thumb that means that high-density patches keep inert individuals (or attract immigrants, Serrano et al., 2004) beyond what the habitat can support. The use of social cues to choose habitats can then lead to spatially biased colony formation, decreased colonization rates and the extinction of subpopulations.

Fletcher (2007) provides a good empirical example of a situation in which social cue use can depend on population density: for least flycatchers Empidonax minimum habitat saturation and costs of competition appeared to outweigh benefits from conspecific attraction when densities were high. This is at least qualitatively in agreement with the model of
Greene (2003) that assumes that individuals are able to assess their performance post-settlement given the current density. However there is a dearth of studies investigating which information-use strategies might be best for overall population performance. The study of Vuilleumier \& Perrin (2006), described in more detail below, indicates that less information may sometimes be beneficial for populations.

In sum we can say that depending on the type of information that serves as a basis for the dispersal choice individuallevel adaptations may not benefit the population. Public information may lead to informational cascades or personal information may lead dispersers into ecological traps (Kokko \& Sutherland, 2001). These individual 'mistakes' are likely to be suboptimal both for the individual and at the population level, and the suboptimality may be caused by environmental changes so that individuals are no longer adapted to the current environment. Additionally, prospecting individuals may also be inert in the sense that their prospecting efforts are perfectly adapted at the individual level giving the best individual response to the environment, but lower (or higher) than what would be optimal for the population.

\section{(2) The effect of cognitive constraints}

Thus far we have concentrated on dispersal (e.g. rates, distances) or prospecting behaviour as traits that can have consequences for individual fitness and population performance simultaneously. However individuals obviously possess plenty of traits that influence how easily their populations find new habitats, even though the initial evolution of these traits was perhaps not related to dispersal per se. One could imagine that whatever the evolutionary reason behind a better ability to disperse, or improved ability to sample habitats efficiently (e.g. better sensory systems that allow detecting suitable habitat from a distance), this will lead to improved ability of populations to colonize and occupy habitats.

Recently, several modelling studies have attempted to focus more explicitly on the effect of animals' cognitive abilities when moving in heterogeneous landscapes (Cramer \& Portier, 2001; Olden et al., 2004; Vuilleumier \& Perrin, 2006), showing that cognitive abilities affect both patch detection and connectivity in the context of metapopulation. Pe 'er \& Kramer-Schadt (2008) found that increasing the perceptual range of the animals can enhance connectivity substantially. However, this positive effect could be counteracted in an intriguing way: whenever cognitive abilities are compromised, this may mean that a substantial proportion of individuals fail to find the most obvious settlement location, and when they have to search more widely, the net effect is that the population as a whole becomes better connected (Vuilleumier \& Perrin, 2006). Indeed, Vuilleumier \& Perrin (2006) found that animals with no perception of their environments at all led to the healthiest (best connected) metapopulation structure, at least when they had sufficient energy reserves to complete the journey. Thus, even though acquiring information may be expected to enhance individual fitness, more information does not necessarily mean good population performance. 
Intriguingly, both Vuilleumier \& Perrin (2006) and Pe`er \& Kramer-Schadt (2008) conducted their simulations in spatially realistic settings using real-life maps. General theory on when information use leads to positive or negative population consequences is, by contrast, lacking. In this context Barton et al. (2009) show an interesting effect that is probably worth following up with more general models. They demonstrated that the details of information use in movement strategies can evolve depending upon the hostility of the matrix habitat (habitat unsuitable for settlement). When the matrix is relatively benign, individuals are not predicted to bias their movement towards a non-natal patch until they are very close to it. Individuals emigrating from one patch will then reach a large number of different patches, resulting in a wellconnected metapopulation. But when the matrix is hostile, a strategy evolves where individuals move in very straight lines and, as soon as they perceive a non-natal patch, they move directly towards it. This minimises individual dispersal mortality but results in a poorly connected metapopulation.

\section{CONCLUSIONS}

(1) Dispersal is one of the most important life-history traits as well as a fundamental determinant of population connectivity and persistence. Its rates and strategies influence how populations can respond to substantial environmental stress (e.g. human alteration and climate warming) and local catastrophes. Deriving predictive models of dispersal evolution is arguably a harder task than of many other traits, because spatial structure introduces an additional element of complexity in fitness calculations (Metz \& Gyllenberg, 2001) which implicitly means that studies have to consider different levels of selection simultaneously (Olivieri \& Gouyon, 1997).

(2) Despite there being an increased appetite for studying eco-evolutionary feedbacks (Post \& Palkovacs, 2009) and negative population consequences of behaviours selected for (Rankin et al., 2007), researchers rarely engage in quantitative assessment by how much, and under what conditions, naturally selected behaviour is expected to fail to promote population persistence or other measures of population-wide performance. As a consequence, we currently do not know if inertia (too little movement compared with the 'ideal' for a population) is the rule, or if hypermobility (too much movement) is a frequent outcome. Theoretical studies suggest that either is possible, but we lack a solid framework to predict what determines the expected outcome, and models rarely take genetic effects into account. Empirically, data have rarely been systematically presented to answer this question, but inertia appears potentially common while there are also some exciting recent results that appear to support hypermobility.

(3) We have here defined inertia along one specific dimension, by comparing rates of dispersal. In general, there are many dimensions along which traits can fail to optimize population performance. In the context of dispersal, our suggested terms 'inertia' and 'hypermobility' are only meaningful for those dispersal traits that can be quantified easily along a single numerical axis: 'more' dispersal could mean a higher rate, or longer distance, but both allow us to examine if individuals disperse 'too little' or 'too much' and thus decide between inertia and hypermobility. This does not mean that dispersal could not have many more dimensions that create conflict between individual- and population-level good. Often the identity of dispersers matters (see Stevens, Turlure \& Baguette, 2010 for a meta-analysis showing the importance of interindividual differences in dispersal): e.g. do strong individuals evict their weaker siblings that are unlikely to disperse successfully, or do strong and likely successful prospectors instead leave? Population performance might also improve if individuals varied in their dispersal probability. Thus, in certain systems individual variation in their dispersal propensity could represent another dimension of dispersal along which one could find evidence of a discrepancy between population- and individual-level good (for a recent example with bimodal distributions see Starrfelt \& Kokko, 2010). Despite the fact that we cannot logically quantify these as 'inertia', such related concepts are equally worthy of study (see Clobert et al., 2009).

(4) The study of dispersal has recently progressed towards a mechanistic approach that explicitly dissects this process into its three consecutive stages: emigration, transfer and immigration (Clobert et al., 2009, Gibbs et al., 2010). In our modelling examples, we have assumed dispersal costs to be paid at just one stage (emigration). However, costs may accrue at any of the three different dispersal stages. As a result of trade-offs, costs taken at one stage may decrease costs paid at other stages, and the shape of these trade-offs may impact on the evolution of dispersal strategies (J.M.J. Travis, K. Mustin, K. Barton, T.G. Benton, J. Clobert, M.M. Delgado, T. Hovestadt, S.C.F. Palmer, H. Van Dyck \& D. Bonte, in preparation). The shape and identity of trade-offs between dispersal and other lifehistory characteristics is an obvious area with interesting, yet understudied, population consequences - including the links between dispersal and the maintenance of populationlevel good via social behaviour (Hochberg, Rankin \& Taborsky, 2008).

(5) In species with advanced cognitive or sensory abilities, information acquisition and use by individuals during a prospecting process is similarly of crucial importance in linking individual behaviour to population dynamics and distribution (Reed et al., 1999 and references therein; Vuilleumier \& Perrin, 2006). While examples have shown that the use of information in dispersal decisions can be either beneficial or - surprisingly - detrimental at the population level (e.g. Ruxton \& Rohani, 1999; Vuilleumier \& Perrin, 2006), little is known about the general patterns of when information use is beneficial for the population and which prospecting strategies can potentially be detrimental for the population.

(6) We hope that the very failure of our review to provide conclusive answers shows that this is a field in which there is much to do. We have briefly sketched some theoretical 
examples, and many existing models could, regardless of their approach (simulation or otherwise) with relatively little effort be extended to quantify explicitly population consequences of evolved (versus other hypothetical) dispersal rates or distances. The matter is certainly important not merely as a theoretical exercise: managers of endangered species often have to consider whether translocations of individuals could prove beneficial, or whether the converse is true and individuals roam too widely e.g. into dangerous habitats (ecological traps), perhaps necessitating cue manipulations or even physical barriers to keep them in safer environments.

(7) Since the natural ecological context of populations is what fuels evolutionary changes at the individual level, and the evolutionary change in individual life-history traits feeds back to induce shifts in population dynamics (Ronce \& Olivieri, 2004), it is essential to identify and characterize the importance of the different factors that may generate or trigger dispersal and prospecting behaviours as a necessary first step to enhance our understanding at other levels. It is nevertheless also time for researchers to start to look at several levels of selection or adaptation simultaneously when studying these questions both theoretically and empirically.

\section{ACKNOWLEDGEMENTS}

We thank W. Vahl, J. Starrfelt, C. Meier, K. Heubel, V. Penteriani and two anonymous reviewers for providing valuable comments on a previous version of this review. Funding was provided by the Academy of Finland and the Spanish Ministry of Science and Innovation (CGL200802871/BOS). M.M.D. was funded by a postdoctoral grant of the Spanish Ministry of Education.

\section{REFERENCES}

Ahlering, M. A. \& Faaborg, J. (2006). Avian habitat management meets conspecific attraction: if you built it, they will come? Auk 123, 301-312.

Andreassen, H. P. \& Ims, R. A. (2001). Dispersal in patchy vole populations: role of patch configuration, density dependence, and demography. Ecology 82, 2911 - 2926.

Arnold, G. W., Steven, D. E. \& Weeldenburg, J. R. (1993). Influences of remnant size, spacing pattern and connectivity on population boundaries and demography in euros Macropus robustus living in fragmented landscape. Biological Conservation 64, $219-230$

Barton, K. A., Phillips, B. L., Morales, J. M. \& Travis, J. M. J. (2009). The evolution of an 'intelligent' dispersal strategy: biased, correlated random walks in patchy landscapes. Oikos 118, 309-319.

Baskett, M. L., Weitz, J. S. \& Levin, S. A. (2007). The evolution of dispersal in reserve networks. American Naturalist 170, 59-78.

Bell, G. \& Collins, S. (2008). Adaptation, extinction and global change. Evolutionary Applications 1, 3-16.

Bell, G. \& Gonzalez, A. (2009). Evolutionary rescue can prevent extinction following environmental change. Ecology Letters 12, 942-948.

Bonte, D. (2009). Inbreeding depresses short and long distance dispersal modes in three congeneric spiders. Journal of Evolutionary Biology 22, 1424-1429.

Bonte, D., Hovestadt, T. \& Poethke, H.-J. (2009). Sex-specific dispersal and evolutionary rescue in metapopulations infected by male killing endosymbionts. BMC Evolutionary Biology 9, 16.

Boudjemadi, K., Lecomte, J. \& Clobert, J. (1999). Influence of connectivity on demography and dispersal in two contrasting habitats: an experimental approach. Journal of Animal Ecology 68, $1207-1224$.
Boulinier, T. \& Danchin, E. (1997). The use of conspecific reproductive success for breeding patch selection in terrestrial migratory species. Evolutionary Ecology 11, $505-517$.

Bowler, D. E. \& Benton, T. G. (2005). Causes and consequences of animal dispersal strategies: relating individual behaviour to spatial dynamics. Biological Reviews 80, $205-225$.

Bowler, D. E. \& Benton, T. G. (2009). Impact of dispersal on population growth: the role of inter-patch distance. Oikos 3, 403-412.

Brooker, R. W., Travis, J. M. J., Clark, E. J. \& Dytham, C. (2007). Modelling species' range shifts in a changing climate: The impacts of biotic interactions, dispersal distance and the rate of climate change. Journal of Theoretical Biology 24.5, $59-65$.

Bruinzeel, L. W. \& van de Pol, M. (2004). Site attachment of floaters predicts success in territory acquisition. Behavioral Ecology 15, 290-296.

Cadet, C. R., Ferrière, R. \& Metz, J. A. J. (2003). The evolution of dispersal under demographic stochasticity. American Naturalist 162, 427-441.

Citta, J. J. \& Lindberg, M. S. (2007). Nest-site selection of passerines: effects of geographic scale and public and personal information. Ecology 88, 2034-2046.

Clobert, J., Danchin, E., Dhondt, A. A. \& Nichols, J. (2001). Dispersal. Oxford University Press, New York.

Clobert, J., Le Galliard, J.-F., Cote, J., Meylan, S. \& Massot, M. (2009). Informed dispersal, heterogeneity in animal dispersal syndromes and dynamics of spatially structures populations. Ecology Letters 12, $197-209$.

Cody, L. M. \& Overston, J. Mc. (1996). Short-term evolution of reduced dispersal in island plant populations. Journal of Ecology 84, 53-61.

Comins, H. N. (1982). Evolutionarily stable strategies for localized dispersal in two dimensions. Journal of Theoretical Biology 94, 579-606.

Comins, H. N., Hamilton, W. D. \& May, R. M. (1980). Evolutionarily stable dispersal strategies. Journal of Theoretical Biology 82, $205-230$.

Cooper, C. B. \& Walters, J. R. (2002). Experimental evidence of disrupted dispersal causing decline of an Australian passerine in fragmented habitat. Conservation Biology $16,471-478$.

Cooper, C. B., Walters, J. R. \& Priddy, J. (2002). Landscape patterns and dispersal success: simulated population dynamics in the brown treecreeper. Ecological Applications 12, $1576-1587$.

Cramer, P. C. \& Portier, K. M. (2001). Modeling Florida panther movements in response to human attributes of the landscape and ecological settlings. Ecological Modelling 140, $51-80$.

Cronin, J. T. (2007). From population sources to sieves: The matrix alters hostparasitoid source-sink structure. Ecology 88, 2966-2976.

Cushman, S. A. (2006). Effects of habitat loss and fragmentation on amphibians: A review and prospectus. Biological Conservation 128, $231-240$.

Dale, S. (2001). Female-biased dispersal, low female recruitment, unpaired males, and the extinction of small isolated bird populations. Oikos 92, 344-356.

Dall, S. R. X., Giraldeau, L.-A., Olsson, O., McNamara, J. \& Stephens, D. W. (2005). Information and its use by animals in evolutionary ecology. Trends in Ecology \& Evolution 20, $187-193$

Danchin, E., Giraldeau, L.-A., Valone, T. \& Wagner, R. H. (2004). Public information: from noisy neighbors to cultural evolution. Science 305, 487-491.

Delgado, M. M., Penteriani, V., Nams, V. O. \& Campioni, L. (2009). Changes of movement patterns from early dispersal to settlement. Behavioral Ecology and Sociobiology 64, $35-43$.

Delgado, M. M., Penteriani, V., Revilla, E. \& Nams, V. O. (2010). The effect of phenotypic traits and external cues on natal dispersal movements. Journal of Animal Ecology 79, 620-632.

Denno, R. F., Hawthorne, D. J., Thorne, B. L. \& Gratton, C. (2001). Reduced flight capability in British Virgin Island populations of a wing-dimorphic insect: the role of habitat isolation, persistence and structure. Ecological Entomology 26, 25-36.

Dieckmann, U. \& Metz, J. A.J. (2006). Surprising evolutionary predictions from enhanced ecological realism. Theoretical Population Biology 69, 263-281.

Doligez, B., Cadet, C., Danchin, E. \& Boulinier, T. (2003). When to use public information for breeding habitat selection? Animal Behaviour 66, 973-988.

Doligez, B.\& Pä rt, T. (2008). Estimating fitness consequences of dispersal: a road to 'know-where'? Non-random dispersal and the underestimation of dispersers' fitness. Journal of Animal Ecology 77, 1199 - 1211.

Doligez, B., Pärt, T., Danchin, E., Clobert, J. \& Gustafsson, L. (2004). Availability and use of public information and conspecific density for settlement decisions in the Collared flycatcher. Journal of Animal Ecology 73, 75-87.

Dytham, C. \& Travis, J. M. J. (2006). Evolving dispersal and age at death. Oikos 113, $530-538$.

Enfjä11, K. \& Leimar, O. (2009). The evolution of dispersal-the importance of information about population density and habitat characteristics. Oikos 118, $291-299$.

Fiegna, F. \& Velicer, G. J. (2003). Competitive fates of bacterial social parasites: persistence and self-induced extinction of Myxococcus xanthus cheaters. Proceeding of the Royal Society Academy of London B 270, 527 - 1534 .

Fisher, R. A. (1958). The Genetical Theory of Natural Selection. Dover, New York. 
Fletcher, R. J. Jr. (2007). Species interactions and population density mediate the use of social cues for habitat selection. Journal of Animal Ecology 76, 598-606.

Forero, M., Donázar, J. A. \& Hiraldo, F. (2002). Causes and consequences of natal dispersal in a population of Black kites. Ecology 83, 858-872.

Frank, S. A. \& Slatkin, M. (1992). Fisher's fundamental theorem of natural election. Trends in Ecology \& Evolution 7, $92-95$.

Futuyma, D. (1986). Evolutionary Biology. Sinaur Associates, Massachussets.

Futuyma, D. (1998). Evolutionary Biology. Sinauer Associates, Massachussets.

Gandon, S. \& Michalakis, Y. (1999). Evolutionary stable dispersal rate in a metapopulation with extinctions and kin competition. Journal of Theoretical Biology 199, $275-290$.

Gaona, P., Ferreras, P. \& Delibes, M. (1998). Dynamics and viability of a metapopulation of endangered Iberian Lynx (Lynx pardinus). Ecological Monographs $68,349-370$.

Gibbs, J. P. (1998). Distribution of woodland amphibians along a forest fragmentation gradient. Landscape Ecology 13, 263-268.

Gibbs, M., Saastamoinen, M. Coulon, A. \& Stevens, V. (2010). Organisms on the move: ecology and evolution of dispersal. Biology Letters 6, 146-148.

Gilroy, J. J. \& Sutherland, W. J. (2007). Beyond ecological traps: perceptual errors and undervalued resources. Trends in Ecology \& Evolution 22, 351 - 356.

Giraldeau, L.-A., Valone, T. J. \& Templeton, J. J. (2002). Potential disadvantage of using socially acquired information. Philosophical Transactions of the Royal Society of London B 357, 1559 - 1566 .

Green, D. M. (2003). The ecology of extinction: population fluctuation and decline in amphibians. Biological Conservation 111, $331-343$.

Greene, C. M. (2003). Habitat selection reduces extinction of populations subject to Allee effects. Theoretical Population Biology 64, 1-10.

Gyllenberg, M. \& Parvinen, K. (2001). Necessary and sufficient conditions for evolutionary suicide. Bulletin of Mathematical Biology 63, 981-993.

Gyllenberg, M., Parvinen, K. \& Dieckmann, U. (2002). Evolutionary suicide and evolution of dispersal in structured metapopulations. Journal of Mathematical Biology $45,79-105$.

Hagan, J. M., Vander Haegen, W. M. \& McKinley, P. S. (1996). The early development of forest fragmentation effects on birds. Conservation Biology 10, 188-202.

Haldane, J. B. S. (1932). The causes of Evolution. Green \& Co. Limited. Longmans, London.

Hamilton, W. D. \& May, R. M. (1977). Dispersal in stable habitats. Nature 269, $578-581$.

Hanski, I. (1998). Metapopulation dynamics. Nature 396, $41-49$.

Hanski, I. \& Gaggiotti, O. E. (2004). Ecology, genetics and evolution of metapopulations. Elsevier Academic Press, Amsterdam.

Hansson, B., Bensch, S. Hasselquist, D. \& Nielsen, B. (2002). Restricted dispersa in a long-distance migrant bird with patchy distribution, the great reed warbler. Oecologia 130, 536-542.

Heino, M. \& Hanski, I. (2001). Evolution of migration rate in a spatially realistic metapopulation model. American Naturalist 157, 495-511.

Hochberg, M. E., Rankin, D. J. \& Taborsky, M. (2008). The coevolution of cooperation and dispersal in social groups and its implications for the emergence of multicellularity. BMC Evolutionary Biology 8, 238.

Kisdi, E. (2004). Conditional dispersal under kin competition: extension of the Hamilton-May model to brood size-dependent dispersal. Theoretical Population Biology $66,369-380$.

Kisdi, É. (2010). Costly dispersal can destabilize the homogeneous equilibrium of a metapopulation. Journal of Theoretical Biology 262, 279-283.

Kneitel, J. M. \& Miller, T. E. (2003). Dispersal rates affects species composition in metacommunities of Sarracenia purpurea inquilines. American Naturalist 162, 165-171.

Kokko, H. (2007). Modelling for Field Biologists (and Other Interesting People). Cambridge University Press, Cambridge.

Kokko, H. \& Ló pez-Sepulcre, A. (2006). From individual dispersal to species ranges: perspectives for a changing world. Science 313, 789-791.

Kokko, H. \& Ló pez-Sepulcre, A. (2007). The ecogenetic link between demography and evolution: can we bridge the gap between theory and data? Ecology Letters 10, $773-782$.

Kokko, H. \& Sutherland, W. J. (2001). Ecological traps in changing environments: Ecological and evolutionary consequences of a behaviourally mediated Allee effect. Evolutionary Ecology Research 3, $537-551$.

Komdeur, J. (1996). Facultative sex ratio bias in the offspring of Seychelles warblers. Proceeding of the Royal Society of London B 263, 661 -666.

Kosciuch, K. L. \& Langerhans, R. B. (2004). Evolution of coloniality via commodity selection: what about variance? Auk 121, 257-262.

Laan, R \& Verboorn, B. (1990). Effects of Pool Size and Isolation on Amphibian Communities. Biological Conservation 54, 251-262.

Laiolo, P. \& Tella, J. L. (2008). Social determinants of songbird vocal activity and implications for the persistence of small populations. Animal Conservation 11, 443-44.1.

Lambin, X., Aars, J. \& Piertney, S. B. (2001). Dispersal, intraspecific competition, kin competition and kin facilitation: a review of the empirical evidence. In Dispersa (ed.J. Clobert, E. Danchin, A. A. Dhondt and J. D. Nichols), pp. 110-122. Oxford University Press, New York.
Lande, R. (1987). Extinction thresholds in demographic models of territorial populations. American Naturalist 130, 624-635.

Levins, R. (1970). Extinction. In Some mathematical questions in biology (ed. M. Gerstenhaber), pp. 70-170. Proceedings of the Second Symposium on Mathematical Biology held in New York December, 1967 and the Third Symposium on Mathematical Biology held in Dallas, December 1968. Rhode Island: American Mathematical Society, Providence.

López-Sepulcre, A. \& Kokko, H. (2005). Territorial defense, territory size and population regulation. American Naturalist 166, 317-329.

López-Sepulcre, A., Norris, K. \& Kokko, H. (2009). Reproductive conflict delays the recovery of an endangered social species Journal of Animal Ecology 78, 219-225.

Matsuda, H. \& Abrams, P. A. (1994). Runaway evolution to self extinction under asymmetrical competition. Evolution 48, 1764-1772.

Matthiopoulos, J., Harwood, J. \& Thomas, L. (2005). Metapopulation consequences of site fidelity for colonially breeding mammals and birds. Journal of Animal Ecology 74, 716-727.

Maynard Smith, J. (1976). Group selection. Quarterly Review of Biology 51, 277 - 283.

McCarthy, M. A. (1997). Competition and dispersal from multiple nests. Ecology 78, $873-883$.

McCarthy, M. A. (1999). Effects of competition on natal dispersal distance. Ecological Modelling 114, 305-310.

Metz, J. A. J. \& Gyllenberg, M. (2001). How should we define fitness in structured metapopulation models? Including an application to the calculation of evolutionarily stable dispersal strategies. Proceeding of the Royal Society of London B 268, 499-508.

Metz, J. A. J., Mylius, S. D. \& Dieckmann, U. (2008). When does evolution optimize? Evolutionary Ecological Research 10, 629-654.

Muir, W. M. \& Howard, R. D. (1999). Possible ecological risks of transgenic organism release when transgenes affect mating success: Sexual selection and the Trojan gene hypothesis. Proceeding of National Academy of Science 96, 13853-13856. Murrel, D. J., Travis, J. M. J. \& Dytham, C. (2002). The evolution of dispersal distance in spatially-structured populations. Oikos 97, 229-236.

Nocera, J. J., Forbes, G. J. \& Giraldeau, L.-A. (2006). Inadvertent social information in breeding site selection of natal dispersing birds. Proceeding of the Royal Society of London B 273, 349-355.

Olden, J. D., Schooley, K. L., Monroe, J. B. \& Poff, N. L. (2004). Contextdependent perceptual ranges and their relevance to animal movement in landscapes. Journal of Animal Ecology 73, $1190-1194$.

Olivieri, I. \& Gouyon, P.-H. (1997). Evolution of Migration rate and Other Traits. In Metapopulation Biology (ed. I. Hanski and M. E. Gilpin), pp. 293-324. Academic Press, San Diego.

Olsen, E. M., Heino, M., Lilly, G. R., Morgan, M. J., Brattey, J., Ernande, B. \& Dieckmann, U. (2004). Maturation trends indicative of rapid evolution preceded the collapse of northern cod. Nature 428, $932-935$.

Opdam, P. (1990). Metapopulation theory and habitat fragmentation: a review of Holarctic breeding bird studies. Landscape Ecology 5, 93-106.

Orr, H. A. \& Unckless, R. L. (2008). Population extinction and the genetics of adaptation. American Naturalist 172, 160-169.

Parejo, D., Oro, D. \& Danchin, E. (2006). Testing habitat copying in breeding habitat selection in a species adapted to variable environments. Ibis 148,146-154.

Parvinen, K. (2004). Adaptive responses to landscape disturbances: theory. In Evolutionary conservation biology (ed. R. Ferrière, U. Dieckmann and D. Couvet), pp. 265-286. Cambridge University Press, Cambridge.

Parvinen, K. (2005). Evolutionary suicide. Acta Biotheoretica 53, 241 - 264.

Parvinen, K. (2007). Evolutionary suicide in a discrete time metapopulation model. Evolutionary Ecology Research 9, 619-633

Pe`er, G. \& Kramer-Schadt, S. (2008). Incorporating the perceptual range of animals into connectivity models. Ecological Modelling 213, 73-85.

Pelletier, F., Garant, D. \& Hendry, A. P. (2009). Eco-evolutionary dynamics. Philosophical Transactions of the Royal Society of London B 364, 1483-1489.

Penteriani, V., Otalora, F. \& Ferrer, M. (2006). Floater dynamics can explain positive patterns of density-dependent fecundity in animal populations. American Naturalist 168, 697-703.

Péron, G., Lebreton, J.-D. \& Crochet, P.-A. (2010). Breeding dispersal in blackheaded gull: the value of familiarity in a contrasted environment. Journal of Animal Ecology 79, $317-326$

Perrin, N. \& Goudet, J. (2001). Inbreeding, kinship, and the evolution of natal dispersal. In Dispersal (ed. J. Clobert, E. Danchin, A. A. Dhondt and J. D. Nichols), pp. 123-142. Oxford University Press, New York.

Post, D. M. \& Palkovacs, E. P. (2009). Eco-evolutionary feedbacks in community and ecosystem ecology: interactions between the ecological theatre and the evolutionary play. Philosophical Transactions of the Royal Society B 346, 1629 - 1640.

Potter, M. A. (1990). Movement of North Island Brown kiwi (Apteryx australis mantelli) between forest remnants. New Zealand Journal of Ecology 14, 17 -24.

Powell, M. G. (2007). Geographic range and genus longevity of the late Paleozoic brachiopods. Paleobiology 33, 530-546.

Rankin, D. J. \& López-Sepulcre, A. (2005). Can adaptation lead to extinction? Oikos $111,616-619$ 
Rankin, D. J., Ló pez-Sepulcre, A., Foster, K. R. \& Kokko, H. (2007). Specieslevel selection reduces selfishness through competitive exclusion. Journal of Evolutionary Biology 20, $1459-1468$.

Reed, D. H. (2005). Relationship between population size and fitness. Conservation Biology 19, $563-568$.

Reed, J. M., Boulinier, T., Danchin, E. \& Oring, L. W. (1999). Informed dispersal: prospecting by birds for breeding sites. Current Ornithology 15, 189-259.

Revilla, E. \& Wiegand, T. (2008). Individual movement behavior, matrix heterogeneity, and the dynamics of spatially structured populations. Proceeding of the National Academy of Sciences of the United States of America 105, 19120 - 19125.

Roff, D. A. (1975). Population stability and the evolution of dispersal in a heterogeneous environment. Oecologia 19, 217-237.

Ronce, O. (2007). How Does It Feel to Be Like a Rolling Stone? Ten Questions About Dispersal Evolution. The Annual Review of Ecology, Evolution, and Systematics 38, $231-53$.

Ronce, O. \& Olivieri, I. (2004). Life history evolution in metapopulations. In Ecology, Genetics, and Evolution of Metapopulations (ed. I. Hanski and O. E. Gaggiotti), pp. 227 - 58. Elsevier Academic Press, Amsterdam.

Ruxton, G. D. \& Rohani, P. (1999). Fitness-Dependent Dispersal in Metapopulations and Its Consequences for Persistence and Synchrony. Journal of Animal Ecology $68,530-539$

Schjørring, S. (2002). The evolution of informed natal dispersal: inherent versus acquired information. Evolutionary Ecology Research 4, 227 - 238.

Schreiber, S. J. (2010). Interactive effects of temporal correlations, spatial heterogeneity and dispersal on population persistence. Proceeding of the Royal Society of London B 266, 969-973.

Schtickzelle, N. \& Baguette, M. (2004). Metapopulation viability analysis of the bog fritillary butterfly using RAMAS/GIS. Oikos 104, $277-290$.

Schtickzelle, N., Mennechez, G. \& Baguette, M. (2006). Dispersal depression with habitat fragmentation in the bog fritillary butterfly. Ecology 87, 1057-1065.

Seppänen, J.-T., Forsman, J. T., Mönkkönen, M. \& Thomson, R. L. (2007). Social information use is a process across time, space, and ecology, reaching the heterospecifics. Ecology 88, $1622-1633$.

Sergio, F. \& Penteriani, V. (2005). Public information and territory establishment in a loosely colonial raptor. Ecology $86,340-346$.

Serrano, D., Forero, M., Donázar, J. A. \& Tella, J. L. (2004). Dispersal and social attraction affect colony selection and dynamics of Lesser kestrels. Ecology 85, $3438-3447$.

Serrano, D., Oro, D., Ursúa, E. \& Tella, J. L. (2005). Colony size selection determines adult survival and dispersal preferences: Allee effects in a colonial bird. American Naturalist 166, E22- E31.

Shah, N. J. \& Parr, S. J. (1999). Inter-island movements by Seychelles magpierobins Copsychus sechellarum: attempts at recolonisation? Bird Conservation International 9, 283-284.

Sharp, S. P., Baker, M. B, Hadfield, J. D, Simeoni, M. \& Hatchwell, B. J. (2008). Natal dispersal and recruitment in a cooperatively breeding bird. Oikos $117,1371-1379$.
Shorrocks, B. \& Rosewell, J. (1987). Spatial patchiness and community structure: coexistence and guild size of drosophilids on ephemeral resources. In Organization of Communities Past and Present (ed. J. H. R. Gee and P. S. Giller), pp. 29 - 51. Blackwell Scientific Publications, Oxford.

Sieving, K. E., Willson, M. F. \& De Santo, T. L. (1996). Habitat barriers to movement of understory birds in fragmented south-temperate rainforest. Auk 113, 944-949.

Spear, L. B., Pyle, P. \& Nur, N. (1998). Natal dispersal in the western gull: proximal factors and fitness consequences. Journal of Animal Ecology 67, 165-179.

Stamps, J. A. (1994). Territorial behavior: testing the assumptions. Advanced in the Study of Behavior 23, $173-232$.

Stamps, J. A. \& Krishnan, V. V. (1999). A learning based model of territory establishment. Quarterly Review of Biology 74, 291 - 318.

Stamps, J. A. \& Krishnan, V. V. (2001). How territorial animals compete for divisible space: a learning-based model with unequal competitors. American Naturalist 157, $154-169$.

Starrfelt, J. \& Kokko, H. (2010). Parent offspring conflict and the evolution of dispersal distance. American Naturalist 175, 38-49.

Stevens, V., Turlure, C. \& Baguette, M. (2010). A meta-analysis of dispersal in butterflies. Biological Reviews 85, 625-642.

Strong, A. \& Bancroft, G. T. (1994). Postfledging dispersal of White-crowned Pigeons: implications for conservation of deciduous seasonal forest in the Florida Keys. Conservation Biology 8, 770 - 779 .

Thomas, C. D. (2000). Dispersal and extinction in fragmented landscapes. Proceedings of the Royal Society of London B 267, $139-145$.

Thomas, C. D., Franco, A. M. A. \& Hill, J. K. (2006). Range retractions and extinction in the face of climate warming. Trends in Ecology \& Evolution 21, $415-416$.

Travis, J. M. J. \& Dytham, C. (1999). Habitat persistence, habitat availability and the evolution of dispersal. Proceedings of the Royal Society of London B 266, $723-728$.

Travis, J. M. J., Mustin, K., Benton, T. G. \& Dytham, C. (2009). Accelerating invasion rates result from the evolution of density of density-dependent dispersal. Journal of Theoretical Biology 259, $151-158$.

Travis, J. M. J., Smith, H. S. \& Ranwala, S. M. W. (2010). Towards a mechanistic understanding of dispersal evolution in plants: conservation implications. Biodiversity Research 16, 690-702.

Van Valen, L. (1971). Group selection and the evolution of dispersal. Evolution 25, $591-598$.

Vögeli, M., Serrano, D., Pacios, F. \& Tella, J. L. (2010). The relative importance of patch habitat quality and landscape attributes on a declining steppe-bird metapopulation. Biological Conservation 143, 1057-1067.

Vuilleumier, S. \& Perrin, N. (2006). Effects of cognitive abilities on metapopulation connectivity. Oikos 113, 139-147.

Wright, S. D., Gillman, L. N., Ross, H. A. \& Keeling, D. J. (2009). Slower tempo of microevolution in island birds: implications for conservation biology. Evolution 63, $2275-2287$ 